\title{
Changing Trend of Instrumental Vaginal Deliveries at Patan Hospital
}

\section{Lamichhane $\mathbf{B}^{1}$, Singh $\mathbf{A}^{2}$}

'Rapti Life Care Hospital, Tulsipur, Dang, ${ }^{2}$ Department of Obstetrics and Gynecology, Patan Academy of Health Sciences, Lalitpur, Nepal.

Received: March 20, 2015 ; Accepted: September 25, 2015

Aims: The aim of the study was to evaluate the changing trend of the instrumental vaginal deliveries at Patan hospital over the last 10 years.

Methods: This was a retrospective study done at Patan hospital. The study included data of 10 years duration (July $15^{\text {th }}, 2004$ - July $\left.14^{\text {th }}, 2014\right)$. The data included total normal delivery, caesarean section, vacuum delivery, forceps delivery and total delivery of the respective years.

Results: Out of 80,149 deliveries over 10 years, $1635(2.03 \%)$ were instrumental vaginal delivery. The study revealed progressive decline in overall trend of instrumental vaginal delivery. The highest percentage of it in the year 2005 was 265 $(16.02 \%)$ and tangential dropped to $49(2.9 \%)$ by 2014 . The study revealed markedly decreased trend in vacuum delivery from 2005 to 2010, but a positive deflection was noticed till 2013, and abrupt fall in the year 2014. Regarding forceps delivery, a gradual fall in trend was noticed over the years. Over the last 10 years the mean percentile value of vacuum delivery was $78.47 \%$ while that of forceps was $21.52 \%$.

Conclusions: The trend of instrumental vaginal delivery has markedly declined. On the other hand, it has shown increasing trend in caesarean delivery.

Keywords: forceps delivery; instrumental vaginal delivery; vacuum delivery.

\section{INTRODUCTION}

Obstructed labor is one of the major causes of maternal death in Nepal. WHO estimates $8 \%$ of maternal death in developing countries is due to obstructed and prolonged labor. ${ }^{1}$ Management of prolonged and obstructed labor requires instrumental vaginal delivery (IVD) or caesarean delivery. Considering the great advantage of proper use of IVD and its better feto-maternal outcome, use of IVD is an essential component of basic emergency obstetric care (BEOC). ${ }^{2}$

The instrumental delivery rate varies greatly between settings. In developed countries, the rate vary from $10-15 \%$ in UK, ${ }^{3}$ to just $4.5 \%$ in USA. ${ }^{4}$ In developing countries the incidence of IVD rate is much lower. There have been reports of variation in the trends of general rate of instrumental vaginal delivery in obstetric practice. ${ }^{5}$ The objective of this study is to evaluate the changing trend of the instrumental

\section{CORRESPONDENCE}

Dr Basant Lamichhane

Rapti Life Care Hospital, Tulsipur, Dang

Email: 1cbasant@gmail.com

Phone: +977-9849157409 vaginal deliveries at Patan hospital, Nepal over the last 10 years.

\section{METHODS}

This was a cross-sectional retrospective study. The study was based on data collected from record section of Patan hospital. The study included data of 10 years duration (July $15^{\text {th }}, 2004$ - July $14^{\text {th }}, 2104$ ). Permission for the study and ethical approval was obtained from the institutional review board (IRB) of Patan Academy of Health Sciences. The data mainly included total normal delivery, caesarean section, vacuum delivery, forceps delivery and total delivery of the respective years. All the data collected were pooled together and recorded and entered in master chart. Data analysis was done by Computer program SPSS version 17.

\section{RESULTS}

Among 80,149 cases delivered at Patan hospital from July $15^{\text {th }}, 2004$ to July $14^{\text {th }}, 2014$, there were $1635 / 80,149(2.03 \%)$ instrumental vaginal deliveries. The total normal vaginal delivery was 51,246 $(63.93 \%)$ and the total number of caesarean section 
was $27,268 / 80,149(34.02 \%)$ over the study duration.

Of the instrumental deliveries vacuum delivery was conducted in $1322(80.85 \%)$ while forceps delivery was conducted in $313(19.15 \%)$ cases.

The overall trend of instrumental vaginal delivery has progressively declined. The highest percentage of IVD was in the year 2005, $265(16.02 \%)$ and has tangential dropped to $49(2.9 \%)$ by 2014 . In the year 2012 there was slight increment in the percentage of IVD but since then the trend has markedly declined (Figure 1).

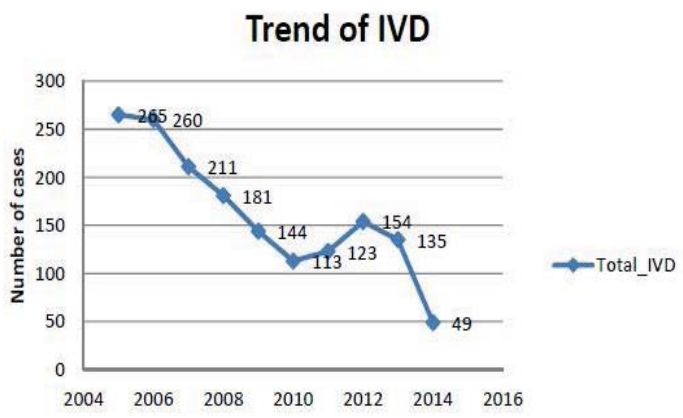

Figure 1. Trend of IVD

Regarding the type of IVD, vacuum delivery was more frequently performed than forceps delivery. The study found markedly decreasing trend of vacuum delivery from 2005 to 2010 , but a positive deflection was noticed in the trend of vacuum delivery till 2013, and abrupt fall in the year 2014 was noticed (Figure 2).

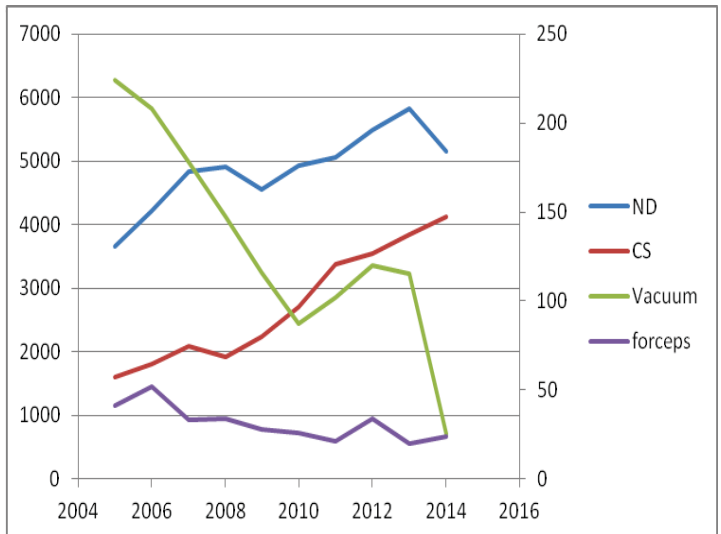

Figure 2. Trends of various mode of delivery versus year

A gradual fall in trend was noticed over the years along with the use of forceps delivery (Figure 2). Over the last 10 years the mean percentile value of vacuum delivery was $78.47 \%$ while that of forceps was $21.52 \%$ (Table 1 ).

Table 1. Annual distribution of instrumental delivery over the study period $(\mathrm{n}=1635)$.

\begin{tabular}{|llll|}
\hline Year & Total- n (\%) & $\begin{array}{l}\text { Vacuum } \\
\text { n (\%) }\end{array}$ & $\begin{array}{l}\text { Forceps } \\
\text { n (\%) }\end{array}$ \\
\hline $2004-2005$ & $265(16.02)$ & $224(84.52)$ & $41(15.47)$ \\
$2005-2006$ & $260(15.90)$ & $208(80.00)$ & $52(20.00)$ \\
$2006-2007$ & $211(12.90)$ & $178(84.36)$ & $33(15.63)$ \\
$2007-2008$ & $181(11.07)$ & $147(81.21)$ & $34(18.78)$ \\
$2008-2009$ & $144(8.80)$ & $116(80.55)$ & $28(19.44)$ \\
$2009-2010$ & $113(6.9)$ & $87(76.99)$ & $26(17.07)$ \\
$2010-2011$ & $123(7.5)$ & $102(82.92)$ & $21(17.07)$ \\
$20111-2012$ & $154(9.41)$ & $120(77.92)$ & $34(22.07)$ \\
$2012-2013$ & $135(8.25)$ & $115(85.15)$ & $20(14.81)$ \\
$2013-2014$ & $49(2.99)$ & $25(51.02)$ & $24(49.98)$ \\
\hline
\end{tabular}

Note: ND - Normal delivery; CS - Caesarean section. The time duration in the table includes July $15^{\text {th }}$ of preceding year to July $14^{\text {th }}$ of next year.

Interestingly along with the falling trend of IVD, the progressive increase in the trend of cesarean delivery was noticed (Figure 2). The rate of cesarean section was $22.84 \%$ in 2005 that progressively increased and reached $44.38 \%$ in 2014 (Figure 2). This waxing trend in caesarean delivery is the most possible explanation of declining trend in IVD. Similarly the trend of normal delivery over the years was found to decline. The percentage of normal vaginal delivery was $73.40 \%$ in 2005 and it dropped to $55.10 \%$ in 2014.

\section{DISCUSSION}

The overall rate of instrumental delivery of the study was $2.03 \%$ of the total deliveries, which almost resembled to that of developing countries of Africa. The rate of instrumental delivery at Patan hospital $(2.03 \%)$ was comparable to $2 \%$ in Maidugiri, Nigeria, 2.1\% Abakaiaki, Nigeria, and 2.3\% Younde, Cameroon. ${ }^{6}$ The rate of IVD of the study $(2.03 \%)$ was found higher as compared $0.69 \%$ to Bauchi, Nigeria. ${ }^{7}$ On the other hand, as compared to developed countries the percentage of IVD at Patan Hospital was much lower. The percentage of IVD was $16 \%$ in Canada, $11 \%$ in England, $10 \%$ in USA, 14\% in Australia, and $10 \%$ in Denmark which were much higher than that of this study. ${ }^{8}$ Vacuum extraction has largely replaced forceps delivery in most developing countries, and Northern Europe. ${ }^{9}$ Likewise this study has also revealed the popularity of vacuum over forceps. 
The low rate of instrumental delivery in developing countries like Nepal could be attributed to increasing caesarean delivery. The possible explanations of early decision for caesarean delivery could be due to increasing use of cardiotopography (CTG), Ultrasonography (USG), and reluctance among clinicians for long trail of labor and conducting instrumental delivery. These all lead directly to less number of cases attaining second stage of labor which in turn resulted in decreased rate of IVD. Caesarean delivery rates also have an effect; with the rate of IVD inversely proportional to the CS rate. ${ }^{10}$ The other argument in use of IVD is linked to potential trauma to fetus and mother. This hold true only if one fails to make the judicious use of instrumental delivery. Murphy et al. compared early maternal and neonatal complications with cesarean delivery versus instrumental delivery. ${ }^{11}$ They found that women with instrumental deliveries experience less hemorrhage, required less opiates or catherization and were more likely to be discharged within 48 hours. In poor resource settings like ours, the financial burden of caesarean delivery cannot be underestimated. The cost of cesarean delivery is almost four times higher than an IVD. Therefore promoting IVD can be cost saving and it will minimize risk of major abdominal surgery and subsequent future pregnancy complications associated with scarred uterus.

According to World Health Organization assisted vaginal delivery is one of the six components of basic emergency Obstetric care. ${ }^{2}$ Despite this fact, the trend in its use has declined. The practice of IVD must be reintroduced to prevent it from disappearing. WHO and other international and national organizations can play an important leadership and advocacy role in promoting the use of IVD.

\section{CONCLUSIONS}

The study concluded that the trend of instrumental vaginal delivery has markedly declined in Patan hospital. Apart from this, it showed increasing trend of caesarean delivery. Instrumental vaginal delivery should be conducted where it is possible to prevent this disappearing art.

\section{DISCLOSURE}

The authors report no conflicts of interest in this work.

No violation of human rights and safety.

Funding: Nil

\section{REFERENCES}

1. WHO. A mother-baby package: implementing safe motherhood in countries. [Cited 2015 July 19]. Available from http:// apps.who.int/iris/bitstream/10665/63268/1/WHO FHE MSM_94.11_Rev.1.pdf

2. UNICEF, World Health Organization, UNFPA. Guidelines for monitoring the availability and use of obstetric services; 1997. [Cited 2014 June 19]. Available from http://www.who.int/ reproductivehealth/publications/monitoring/9789241547734/ en

3. Royal College of Obstetricians and Gynecologists. Operative vaginal delivery (Guideline 26). [Cited 2015 August 1]. Available from https://www.rcog.org.uk/en/guidelinesresearch-services/guidelines/gtg26/

4. National Vital Statistics Reports, Volume 57, Number 7. January 7, 2009. [Cited 2015 September 9]. Available from http://www.cdc.gov/nchs/data/nvsr/nvsr57/nvsr57_07.pdf

5. Arulkumar S. Malpresentation, malposition, cephalopelvic disproportion and obstetric procedure. Dewhurst's Textbook of Obstetrics and Gynecology. $7^{\text {th }}$ ed. London: Blackwell Publishing; 2007:213-26.
6. Onoh RC, Ezeonu PO, Chijioke O, Onoh TP, Saidu A K, Ezeonu CT. Disappearing art of forceps delivery and the trend of instrumental vaginal deliveries at Abakaliki, Nigeria. Afr J Med Health Sci. 2014;13:99-104

7. Kadas AS, Alliyu LD, Hauwa MA. Instrumental delivery in Bauchi, Northeast Nigeria. J West Afr College Surg. 2011;1(4):18-27.

8. Noton F. International difference in the use of obstetric interventions. JAMA. 1990; 263(24):3286-91.

9. Okeke TC, Ekuwazi KE. Is there still a place for vacuum extraction in modern obstetric practice in Nigeria? Ann Med Health Sci. Res. 2013;3:471-4

10. Ameh $\mathrm{C}$, Weeks $\mathrm{A}$. The role of instrumental vaginal delivery in low resource settings. BJOG. 2009;116:22-5.

11. Bailey PE. The disappearing art of instrumental delivery: time to reverse the trend. Int J Gynecol Obstet. 2005;91:89-96. 